\title{
COVID-19 Exposes Urgent Inequities: A Call to Action for Healthcare Reform
}

\section{Priyanka Bushana1,4, Brandy Seignemartin'2,4,5 Ravneet Kaur Waraich ${ }^{3,4}$, Whitney W. Wood 3,4 ,}

1Washington State University Health Sciences, Elson S. Floyd College of Medicine, Department of Biomedical Sciences, Spokane, WA

${ }^{2}$ Washington State University Health Sciences, College of Pharmacy and Pharmaceutical Sciences, Program in Pharmacy, Spokane, WA

${ }^{3}$ Washington State University Health Sciences, Elson S. Floyd College of Medicine, Program in Medicine, Spokane, WA

${ }^{4}$ Washington State University Health Sciences, Health Sciences Student Advocacy Association, Spokane, WA 5Washington State University Health Sciences, Associated Students of WSU Health Sciences, Spokane, WA http://doi.org/10.38126/ISPG170101

Corresponding author: priyanka.bushana@gmail.com

Keywords: health equity; health policy; health advocacy; COVID-19; healthcare reform; HHS;

Executive Summary: The COVID-19 pandemic has exposed undeniable health inequities among marginalized communities (MC), including black, indigenous, and other people of color (BIPOC) in the United States (Forno and Celedón 2012, Kaiser Family Foundation 2017, US National Center for Health Statistics 2019, Glasgow 2020). The lack of centralized support for local health responses has jeopardized many MC/BIPOC (Baah, Teitelman, and Riegel 2019). We propose the Department of Health and Human Services (HHS) implement the following policy steps:

1. Centrally collect patient data on social determinants of health and equity and post-COVID-19 health outcomes (Paradies et al. 2015, Jones et al. 2009, Magnan 2017). Real-time data collection allows for real-time quality improvement and implementation of policies to mitigate inequities in the short-term.

2. Expand and implement Centers for Medicare and Medicaid (CMS) value-based care models (VBCM) to address inequities in the long-term. VBCMs institutionalize data collection initiated in Step $\mathbf{1}$ while concurrently implementing interventions.

3. Temporarily expand Medicaid coverage for individuals needing subsidized insurance. This provides a safety net for those suffering employment instability during the crisis, alleviating some root causes of health inequities.

These steps will centralize resources, empowering local health systems to control and contain outbreaks disproportionately occurring among MC/BIPOC. HHS is positioned to implement these policies and mitigate further damage from COVID-19. HHS agencies such as the Food and Drug Administration (FDA) and Centers for Disease Control and Prevention (CDC) have successfully implemented centralization responses, such as the U.S. President's Emergency Plan for AIDS Relief (PEPFAR) in response to the HIV/AIDS epidemic, effectively targeting disparities (Valdiserri and Holtgrave 2020). These previous successful responses by the HHS should compel intervention in the present crisis. 


\section{Background}

Preliminary data on COVID-19 reveals significant disparities in health outcomes by race (Forno and Celedón 2012; Kaiser Family Foundation 2017; US National Center for Health Statistics 2019). In 37 states, black Americans are dying from COVID-19 at rates up to $50 \%$ greater than expected (Godoy and Wood 2020). In Michigan, black Americans represent $14 \%$ of the population, but $41 \%$ of COVID-19-related deaths as of May 26th (APM Research Lab 2020). While many reports focus on black Americans, similar effects are being reported in Indigenous (Eschner 2020, CDC 2020), low-income, undocumented immigrant, incarcerated, and disabled populations (Dunn et al. 2020; Page et al. 2020; United Nations 2020).

Health inequities were similarly revealed during the HIV/AIDS epidemic and have since been aggressively targeted by the HHS. Despite these efforts, lack of structural change prevented inequities from being adequately addressed in the wake of other public health emergencies; HHS programs failed to gain comparable ground in a largely black and poor population in the wake of Hurricane Katrina (Rudowitz, Rowland, and Shartzer 2006). The HHS has not fully engaged its capacity to address the same disparities in today's crisis (Valdiserri and Holtgrave 2020; El-Sadr et al. 2012).

These three disasters demonstrate how crises can disproportionately damage MC/BIPOC. This is partly due to disparities in underlying risk factors (Forno and Celedón 2012; Kaiser Family Foundation 2017; US National Center for Health Statistics 2019). For example, Mississippi reports similar rates of diabetes in white and black Mississippians, but diabetes causes more than twice as many deaths in the latter group (Lamees El-sadek, Zhang, and Funchess 2018). Similarly, countless reports document statistically significant disparities in rates of disease and death in MC/BIPOC (Noonan, Velasco-Mondragon, and Wagner 2016; Myers et al. 2015; Krahn, Walker, and Correa-De-Araujo 2015).

Long-standing social determinants of equity (SDOE) operating through social determinants of health (SDOH) creates additional predisposing disparities, including employment as an essential worker and crowded housing conditions (Oppel Jr et al. 2020). To address these disparities, HHS released a statement on June 8 outlining initiatives the agency is currently undertaking to address health disparities; however, these measures do not provide infrastructure for crisis aversion and lasting healthcare reform (HHS 2020).

This memo contextualizes our recommendations with the respective successes and failures of the HHS response to the HIV/AIDS epidemic and Hurricane Katrina. Ignoring the lessons HHS has learned from past health crises will doom us to repeat the same mistakes. Many experts have characterized the cyclical national response to pandemics as "panicneglect-panic-neglect" (Valdiserri and Holtgrave 2020). Neglect will deepen existing inequities in suffering due to COVID-19, and further expand the health gap between marginalized and nonmarginalized communities.

\section{Policy recommendation}

The HHS is uniquely positioned to centralize resources to manage healthcare related to the COVID19 crisis in the following areas:

- Implement large-scale healthcare support systems through a multitude of agencies. In this proposal, we focus on the capacity of the CDC, CMS, and FDA.

- Implement data collection with metrics pertinent to pandemic tracking like PEPFAR and Ending the HIV Epidemic (EHE). These HHS programs already track COVID-19 and health demographic data to redirect resources to pre-identified MC/BIPOC populations (amfAR 2020b; Birx and Achrekar 2020).

- Mobilize and quickly respond during the immediate crisis. In the aftermath of Katrina, HHS was eventually able to develop resources for effective acute use and longer-term healthcare access for MC/BIPOC (Rudowitz, Rowland, and Shartzer 2006; Andrulis, Siddiqui, and Gantner 2007).

\section{i. Disadvantages}

Many of these recommendations carry a fiscal note and the success of these measures relies on compliance from local governments. However, the cost is mitigated by adaptation of pre-existing HHS programs used to address the HIV/AIDS and Katrina crises. Additionally, healthcare providers may perceive an initial increase in regulation as health 
systems are restructured to VBCMs. Currently, CMS also risks disproportionately penalizing VBCMs unless CMS proactively incorporates equity-framed performance measures (American Academy of Family Physicians et al. 2020).

\section{ii. Advantages}

These recommendations provide straightforward guidance to enhance and implement pre-existing models, such as PEPFAR and EHE, VBCM/PCF, Medicaid expansion (Kaiser Family Foundation 2020), targeting both short- and long-term impacts at the intersection of COVID-19 and health disparities. Benefits of similar programs have been observed in the HIV/AIDS crisis and Medicaid expansion after Katrina, in terms of morbidity, mortality, and foreign relations (El-Sadr et al. 2012).

Amalgamated SDOE/SDOH data can be used to direct limited resources to areas with identified inequities and vulnerabilities. Centralized data collection and intervention will help contain and mitigate the spread of COVID-19.

A VBCM paradigm with a broad health equity lens resolves concerns regarding provider autonomy and narrow single-issue responses. Furthermore, a focus on community partnerships will improve population health outcomes and health system relationships.

\section{Steps for implementation}

i. Step 1: Short-term infrastructure - allocation of COVID-19 relief funding

MC/BIPOC suffer due to inequities in SDOH (Taylor 2019). Evidence-based decision-making is crucial to prevent further damage to disadvantaged communities. These inequities are exacerbated by diminishing public health funding, hindering the HHS's ability to gather demographic data and advise the U.S. pandemic response.

We recommend HHS immediately adopt the following, in line with recent recommendations (Warren et al. 2020):

- Increase allocation of funding to the CDC and FDA to support COVID-19 containment, testing, monitoring, and mitigation as recommended by Forman (Forman 2020). This can be practically and inexpensively implemented through existing frameworks such as PEPFAR, which has proven able to maintain treatment resilience during crises (El-Sadr et al. 2012).

- Require all labs to collect and report SDOH/SDOE, including race, work, socioeconomic status, housing status, and food security, and testing data to the CDC (Feeding America 2020; Desilver 2020; Dunn et al. 2020; Patel and McGinnis 2020). Data collected by the COVID Tracking Project shows all but one state reports some type of demographic information for their COVID-19 cases. While race or ethnicity has been identified for $90 \%$ of deaths and roughly half of all cases (Godoy and Wood 2020; Bharel 2020), this data is not being collected consistently and transparent reporting is not required locally or nationally (Prevention 2020). Collecting and reporting this data is vital, as was learned in the aftermath of Katrina; local agencies failed to come to consensus on appropriate data collection parameters, leading to a failure to meet MC disaster preparedness needs (Andrulis, Siddiqui, and Gantner 2007).

- Expand healthcare reporting structures to require collection of all SDOH data on race, work, socioeconomic status, housing status, and food security (Feeding America 2020; Desilver 2020; Dunn et al. 2020). The EHE and PEPFAR Initiatives provide excellent frameworks for this effort and already collect COVID-19 data that is publicly available.

- Incentivize incorporation of the above data into future Electronic Health Record Certification requirements by CMS. These data will be useful in tracking, treating, and mitigating disparate effects of post-COVID-19 outcomes as they emerge. Early research indicates possible impacts to fertility, brain, heart, and mental health (Zhou et al. 2020; Servick 2020; Ma et al. 2020).

Funding for these ventures can be derived from the supplemental awards allocated to health centers in Section 3211 of the Coronavirus Aid, Relief, and Economic Security (CARES) Act or with passage of the next COVID-19 relief bill. These monitoring mechanisms should guide HHS prioritization of available test kits and federal stockpile supplies to areas of greatest need with the goal of reducing 
disparities in outcomes (Prakash 2020; Forman 2020; Patel and McGinnis 2020; Godoy and Wood 2020; Millett et al. 2020).

ii. Step 2: Long-term infrastructure - value-based care with equitable data collection and intervention Since 2012, CMS has employed VBCM programs to incentivize quality of care for Medicare patients (Centers for Medicare and Medicaid 2020). The general aims are to decrease healthcare costs, prioritize population health, and improve individual health outcomes (Centers for Medicare and Medicaid 2020). International programs, like PEPFAR, which incentivize remediation of health disparities through evidence-based, outcome-oriented strategies have been able to address systemic health inequities MC/BIPOC face (Valdiserri and Holtgrave 2020). We propose adjusting current VBCMs, including the Primary Care First (PCF) model (Centers for Medicare and Medicaid 2019).

We recommend CMS implement the following to address disparities in healthcare outcomes for all institutions benefitting from Medicare and Medicaid dollars:

- Integrate and refine equitable metrics for data collection and monitoring population health outcomes. VBCMs should institutionalize data collection mechanisms proposed in Step 1. Additionally, VBCMs should require partnerships with local organizations to form community advisory boards for health systems to ensure MC/BIPOC needs are met (Levi and DeSalvo 2020).

- Integrate formalized Community Needs Assessments and Community Action Plans with community initiatives to assess and address SDOE/SDOH to improve community health (Moody-Williams 2018) as well as direction for health systems to collaborate with community organizations and spend "community benefit dollars" to address relevant issues outside hospitals' direct control, including laws and policies impacting housing, food, and job accessibility (Anderson et al. 2018). Inability to appropriately implement these partnerships has been disastrous in previous public health emergencies. During Katrina, cultural/language barriers, distrust of messengers, and reliance on informal sources of information made it more difficult for public health officials to ensure the safety of disproportionately impacted communities (Andrulis, Siddiqui, and Gantner 2007); on the contrary, PEPFAR was able to handle the same issues in HIV/AIDS work via collaboration with community organizations (Fenton and Valdiserri 2006; Valdiserri and Holtgrave 2020).

- Utilize payment models to incentivize decreases in health disparities. VBCMs should be modified to reward healthcare providers for reducing disparities resulting from SDOE/SDOH. Profitable VBCMs should be incentivized to reinvest in community programs that promote health equity, as previously outlined by health organizations (Mutha et al. 2012; Anderson et al. 2018). States have modeled this by reporting performance measures and quality improvement stratified by SDOE/SDOH; requiring partnering organizations to address racial disparities, with financial accountability contingent on outcome evaluations; incentivizing VBCMs with bonus funds for projects that effectively address SDOE/SDOH; and using SDOE/SDOHadjusted methods for assessing provider performance (Patel and McGinnis 2020; Crumley and McGinnis 2019; Health 2019).

Implementation of these policies should be instituted centrally given their great success during temporary PEPFAR-funded programs in the past (U.S. President's Emergency Plan for AIDS Relief 2020).

iii. Step 3: Disaster Mitigation and Preventative Care Medicaid Coverage Expansion

MC/BIPOC are disproportionately under- and uninsured (Artiga, Orgera, and Damico 2019; Taylor 2019; Kaiser Family Foundation 2017), which has complicated care in a multitude of previous health programs, including EHE (amfAR 2020a). Many SDOE/SDOH impact access to affordable healthcare and preventive care, putting MC/BIPOC at greater risk of infection and severe complications during this pandemic (Promotion 2020).

Employment instability has led to loss of insurance for nearly 27 million during this pandemic, with 
about 5.7 million falling into a coverage gap where they cannot replace their insurance, due to barriers like immigration status (Pifer 2020). Studies estimate up to 16 million more could lose insurance as unemployment rises (Garfield et al. 2020, Garrett and Gangopadhyaya 2020).

We recommend HHS immediately provide temporary federally incentivized Medicaid expansion with broadened Medicaid presumptive eligibility to include vulnerable populations, including essential workers, renters, undocumented immigrants, unemployed, and those in the Medicaid gap. Reform is needed, particularly in Southern states with prohibitive eligibility requirements or without Medicaid expansion. These are diverse populations with poor overall health and significant racial health disparities (Taylor 2019; Foundation 2018). Federal medical assistance percentage (FMAP) can be reinstated to encourage hold-out states to expand (Forman 2020). To prevent ineffective expansion of coverage, states should exclude prohibitive eligibility requirements and the public rule should be overturned (Forman 2020; Taylor 2019).

These measures have already proven possible: in the aftermath of Katrina, an HHS-approved Medicaid waiver program was implemented to provide

\section{References}

21 USC. Sec 321. 2012. "Definitions; Generally." Accessed April 4, 2020. https://uscode.house.gov/view.xhtml?req=(title: 21\%20section:321\%20edition:prelim

42 USC. Sec 262. 2011. "Regulation of Biological Products." Accessed April 4, 2020. https://uscode.house.gov/view.xhtml?req=(title: 42\%20section:262\%20edition:prelim

American Academy of Family Physicians, AAFP, ACP American College of Physicians, AHA American Hospital Association, AMGA American Medical Group Association, AEH America's Essential Hospitals, AAMC Association of American Medical Colleges, FAH Federation of American Hospitals, HCTTF Health Care Transformation Task Force, MGMA Medical Group Management Association, and NAACO National Association of ACOs. 2020. Sign-On Letter to CMS on COVID-19 Impact on Value-Based Models and Programs.

amfAR, The Foundation for AIDS Research. 2020a. amfAR :: Infographic - Context Matters :: The Foundation for AIDS Research :: HIV / AIDS Research. edited by amFAR. temporary coverage to survivors who evacuated Louisiana (Rudowitz, Rowland, and Shartzer 2006; Kaiser Family Foundation 2020). Such measures decrease barriers to healthcare for MC/BIPOC. Furthermore, they decrease the influence of the SDOE on access to quality healthcare, improving long term pandemic-related health outcomes. Additionally, most states expanded Medicaid with negligible costs and in some cases significant savings (Hayes et al. 2020). This short-term measure could lay the foundation for future lasting Medicaid expansion or other healthcare reform.

\section{Conclusion}

If appropriately enacted, these measures will produce resilience in the face of future health emergencies and make a significant investment toward addressing health outcome disparities.

Pandemics unmask existing inequities and amplify intersectional disadvantages (Crenshaw 1990). Our short-term responses to crises set precedent for longterm policies; the COVID-19 response is no different. Therefore, informed decision-making is crucial to prevent further harm to disadvantaged communities.

amfAR, The Foundation for AIDS Research. 2020b. Ending the HIV Epidemic Database.

Anderson, Andrew C, Erin O'Rourke, Marshall H Chin, Ninez A Ponce, Susannah M Bernheim, and Helen Burstin. 2018. "Promoting health equity and eliminating disparities through performance measurement and payment." Health Affairs 37 (3):371-377.

Andrulis, DP, NJ Siddiqui, and JL Gantner. 2007. "Preparing Racially and Ethnically Diverse Communities for Public Health Emergencies." Health affairs 26 (5). https://doi.org/10.1377/hlthaff.26.5.1269.

APM Research Lab, APM. 2020. The Color of Coronavirus. APM Research Lab.

Artiga, Samantha, Kendal Orgera, and Anthony Damico. 2019. "Changes in health coverage by race and ethnicity since implementation of the ACA, 20132017." Kaiser Family Foundation, Issue Brief, February.

Baah, F. O., A. M. Teitelman, and B. Riegel. 2019. "Marginalization: Conceptualizing patient vulnerabilities in the framework of social determinants of health - An integrative review." Nursing Inquiry $26 \quad$ (1):e12268. https://doi.org/10.1111/nin.12268. 
Bharel, Monica. 2020. Order of the Commissioner of Public Health. edited by Department of Public Health. The Commonwealth of Massachusetts: Executive Office of Health and Human Services.

Birx, Deborah, and Angeli Achrekar. 2020. Statement on PEPFAR's action on COVID - United States Department of State. edited by U.S. Department of State.

CDC. 2020. COVID-19 Funding for Tribes | CDC.

Centers for Medicare and Medicaid, CMS. 2019. HHS NEWS: HHS To Deliver Value-Based Transformation in Primary Care I CMS. edited by HHS.

Centers for Medicare and Medicaid, CMS. 2020. "CMS' Value-Based Programs | CMS." [Website]. https://www.cms.gov/Medicare/QualityInitiatives-Patient-Assessment$\underline{\text { Instruments/Value-Based-Programs/Value- }}$ Based-Programs.

Crenshaw, Kimberle. 1990. "Mapping the margins: Intersectionality, identity politics, and violence against women of color." Stan. L. Rev. 43:1241.

Crumley, Diana, and Tricia McGinnis. 2019. "Advancing Health Equity in Medicaid: Emerging Value-Based Payment Innovations." https://www.chcs.org/advancing-health-equityin-medicaid-emerging-value-based-paymentinnovations/.

Desilver, Drew. 2020. Before the coronavirus, telework was an optional benefit, mostly for the affluent few. In FactTank. Pew Research Center: @pewresearch.

Dunn, Caroline G, Erica Kenney, Sheila E Fleischhacker, and Sara N Bleich. 2020. "Feeding Low-Income Children during the Covid-19 Pandemic." New England Journal of Medicine.

El-Sadr, W. M., C. B. Holmes, P. Mugyenyi, H. Thirumurthy, T. Ellerbrock, R. Ferris, I. Sanne, A. Asiimwe, G. Hirnschall, R. N. Nkambule, L. Stabinski, M. Affrunti, C. Teasdale, I. Zulu, and A. Whiteside. 2012. "Scale-up of HIV Treatment Through PEPFAR: A Historic Public Health Achievement." Journal of Acquired Immune Deficiency Syndromes $60 \quad$ (Suppl 3):S96-104. https://doi.org/10.1097/QAI.0b013e31825eb27 b.

Eschner, Kat. 2020. "Native American Nations are even more vulnerable to COVID-19." Popular Science. https://www.popsci.com/story/health/covid19-native-american-navajo-nation/.

Feeding America, FA. 2020. "African American Hunger and Poverty Facts | Feeding America." [Website]. Feeding America. https://www.feedingamerica.org/hunger-inamerica/african-american.
Fenton, K.A., and R.O Valdiserri. 2006. Twenty-five Years of HIV/AIDS--United States, 1981-2006. In MMWR. Morbidity and mortality weekly report, edited by Centers for Disease Control and Prevention: MMWR Morb Mortal Wkly Rep.

Forman, Howard. 2020. "Health Care Priorities For A COVID-19 Stimulus Bill: Recommendations To The Administration, Congress, And Other Federal, State And Local Leaders From Public Health, Medical, Policy And Legal Experts | Health Affairs." https://www.healthaffairs.org/do/10.1377/hblo g20200312.363618/full/.

Forno, Erick, and Juan C Celedón. 2012. Health disparities in asthma. American Thoracic Society.

Foundation, United Health. 2018. America's Health Rankings | 2018 Annual Report. United Health Foundation.

Garfield, Rachel, Gary Claxton, Anthony Damico, and Larry Levitt. 2020. Eligibility for ACA Health Coverage Following Job Loss. @kff.

Garrett, B, and A Gangopadhyaya. 2020. How the COVID-19 Recession Could Affect Health Insurance Coverage. edited by Robert Wood Johnson Foundation: @RWJF.

Glasgow, LaShawn. 2020. "Beyond Lip Service: Taking A Genuine Approach To Tackling COVID-19 (And All) Black-White Health Disparities In The United States | Health Affairs." June 9, 2020. https://ntserver1.wsulibs.wsu.edu:2962/do/10. 1377/hblog20200604.585088/full/.

Godoy, Maria, and Daniel Wood. 2020. "What Do Coronavirus Racial Disparities Look Like State By State?" NPR, 05-30-2020.

https://www.npr.org/sections/healthshots/2020/05/30/865413079/what-docoronavirus-racial-disparities-look-like-state-bystate.

Hayes, Susan, Akeiisa Coleman, Sara Collins, and Rachel Nuzum. 2020. "The Fiscal Case for Medicaid Expansion | Commonwealth Fund." To The Point | Quick Takes on Health Care Policy and Practice, February 15, 2019. https://www.commonwealthfund.org/blog/201 9/fiscal-case-medicaid-expansion.

Health, Bailit. 2019. How States Can Use Measurement as a Foundation for Tackling Health Disparities in Medicaid Managed Care. edited by Robert Wood Johnson Foundation.

HHS. 2020. HHS Initiatives to Address the Disparate Impact of COVID-19 on African Americans and Other Racial and Ethnic Minorities. edited by U.S. DEPARTMENT OF HEALTH AND HUMAN SERVICES. 
Jones, Camara Phyllis, Clara Yvonne Jones, Geraldine S Perry, Gillian Barclay, and Camille Arnel Jones. 2009. "Addressing the social determinants of children's health: a cliff analogy." Journal of Health Care for the Poor and Underserved 20 (4):1-12.

Kaiser Family Foundation, KFF. 2017. Medicaid Enrollment by Race/Ethnicity. @kff.

Kaiser Family Foundation, KFF. 2020. A Comparison of the Seventeen Approved Katrina Waivers. In Kaiser Commission on Medicaid Facts.

Krahn, Gloria L., Deborah Klein Walker, and Rosaly CorreaDe-Araujo. 2015. "Persons With Disabilities as an Unrecognized Health Disparity Population." https://doi.org/10.2105/AJPH.2014.302182.

Lamees El-sadek, MHS, Lei Zhang, and Tanya Funchess. 2018. "Mississippi Health Disparities and Inequities Report." Office of Health Data \& Research, Last Modified December 2018.

Levi, Jeffrey, and Karen DeSalvo. 2020. "Funding For Local Public Health: A Renewed Path For Critical Infrastructure | Health Affairs." Health Affairs Blog, August 22,2017. https://www.healthaffairs.org/do/10.1377/hblo g20170822.061624/full/

Ma, Ling, Wen Xie, Danyang Li, Lei Shi, Yanhong Mao, Yao Xiong, Yuanzhen Zhang, and Ming Zhang. 2020. "Effect of SARS-CoV-2 infection upon male gonadal function: A single center-based study." medRxiv.

Magnan, Sanne. 2017. "Social determinants of health 101 for health care: five plus five." NAM Perspectives.

Millett, GA, AT Jones, D Benkeser, S Baral, L Mercer, C Beyrer, B Honermann, E Lankiewicz, L Mena, JS Crowley, J Sherwood, and P Sullivan. 2020. "Assessing Differential Impacts of COVID-19 on Black Communities." Annals of epidemiology. https://doi.org/10.1016/i.annepidem.2020.05.0 $\underline{03}$.

Moody-Williams, Jean D. 2018. Value Based Care. edited by Centers for Medicare and Medicaid: HRSA.

Mutha, Sunita, Angela Marks, Ignatius Bau, and Marsha Regenstein. 2012. Bringing Equity into Quality Improvement: An Overview of the Field and Opportunities Ahead. edited by UCSF Center for Health Professions: UCSF.

Myers, H. F., G. E. Wyatt, J. B. Ullman, T. B. Loeb, D. Chin, N. Prause, M. Zhang, J. K. Williams, G. M. Slavich, and H. Liu. 2015. "Cumulative Burden of Lifetime Adversities: Trauma and Mental Health in LowSES African Americans and Latino/as." Psychol $\begin{array}{lll}\text { Trauma } & 7 & \text { (3):243-51. }\end{array}$ https://doi.org/10.1037/a0039077.
Noonan, Allan, Hector Eduardo Velasco-Mondragon, and Fernando A. Wagner. 2016. "Improving the health of African Americans in the USA: an overdue opportunity for social justice." Public Health $\begin{array}{lll}\text { Reviews } & 37 & \text { (1):1-20. }\end{array}$ https://doi.org/doi:10.1186/s40985-016-00254.

Oppel Jr, RJ, R Gebeloff, KKR Lai, W Wright, and M Smith. 2020. "The fullest look yet at the racial inequity of coronavirus." The New York Times, July 5.

Page, Kathleen R, Maya Venkataramani, Chris Beyrer, and Sarah Polk. 2020. "Undocumented US Immigrants and Covid-19." New England Journal of Medicine.

Paradies, Yin, Jehonathan Ben, Nida Denson, Amanuel Elias, Naomi Priest, Alex Pieterse, Arpana Gupta, Margaret Kelaher, and Gilbert Gee. 2015. "Racism as a determinant of health: a systematic review and meta-analysis." PloS one 10 (9).

Patel, Shilpa, and Tricia McGinnis. 2020. "Inequities Amplified By COVID-19: Opportunities For Medicaid To Address Health Disparities | Health Affairs." Health Affairs Blog, May 29, 2020. https://www.healthaffairs.org/do/10.1377/hblo g20200527.351311/full/.

Pifer, Rebecca. 2020. 27M Americans may have lost jobbased health insurance due to COVID-19 downturn. edited by HealthCare Dive: @healthcaredive.

Prakash, Nidhi. 2020. "Doctors Are Concerned That Black Communities Might Not Be Getting Access To Coronavirus Tests." Buzzfeed News, March, 22, 2020.

https://www.buzzfeednews.com/article/nidhipr akash/coronavirus-tests-covid-19-black.

Prevention, Centers for Disease Control and. 2020. "COVIDNET: COVID-19-Associated Hospitalization Surveillance Network." accessed 08/18/20. https://gis.cdc.gov/grasp/COVIDNet/COVID19 5 html.

Promotion, Office of Disease Prevention and Health. 2020. "Access to Health Services | Healthy People 2020." https://www.healthypeople.gov/2020/topicsobjectives/topic/Access-to-Health-Services.

Rudowitz, R, D Rowland, and A Shartzer. 2006. "Health Care in New Orleans Before and After Hurricane Katrina." Health affairs 25 (5). https://doi.org/10.1377/hlthaff.25.w393.

Servick, Kelly. 2020. "For survivors of severe COVID-19, beating the virus is just the beginning | Science | AAAS." Science, 2020-04-08T10:50:13-04:00. https://www.sciencemag.org/news/2020/04/su rvivors-severe-covid-19-beating-virus-justbeginning. 
Swagel, Philip L. 2019. "Effects of Drug Price Negotiation Stemming From Title 1 of H.R. 3, the Lower Drug Costs Now Act of 2019, on Spending and Revenues Related to Part D of Medicare." Congressional Budget Office. Accessed April 4, 2020b. https://www.cbo.gov/system/files/201910/hr3ltr.pdf.

T1interational. 2018 "Costs and Rationing of Insulin and Diabetes Supplies: Findings from the T1international Patient Survey." Accessed July 16, 2020.

https://www.t1international.com/media/assets/ file/T1International Report -

Costs and Rationing of Insulin Diabetes Suppli es 2.pdf

Taylor, Jamila. 2019. Racism, Inequality, and Health Care for African Americans. The Century Foundation.

United Nations, UN. 2020. Policy Brief: The Impact of COVID-19 on Women. United Nations.

U.S. Government Accountability Office. 2017. "Drug Industry: Profits, Research and Development Spending, and Merger and Acquisition Deals," no. GAO-18-40

(December). https://www.gao.gov//assets/690/688472.pdf/
U.S. President's Emergency Plan for AIDS Relief, PEPFAR. 2020. PEPFAR 2020 Country Operational Plan.

U.S. National Center for Health Statistics, USNCHS. 2019. Health, United States: Spotlight Racial and Ethnic Disparities in Heart Disease. Centers for Disease Control and Prevention: Centers for Disease Control and Prevention.

Valdiserri, R. O., and D. R. Holtgrave. 2020. "Responding to Pandemics: What We've Learned from HIV/AIDS." AIDS and Behavior:1-3. https://doi.org/10.1007/s10461-020-02859-5.

Warren, Elizabeth, Ayanna Pressley, Robin L. Kelly, Kamala D. Harris, and Cory A. Booker. 2020. 2020.03.27 Letter to HHS re racial disparities in COVID response. edited by U.S. Department of Health and Human Services.

Zhou, Fei, Ting Yu, Ronghui Du, Guohui Fan, Ying Liu, Zhibo Liu, Jie Xiang, Yeming Wang, Bin Song, and Xiaoying Gu. 2020. "Clinical course and risk factors for mortality of adult inpatients with COVID-19 in Wuhan, China: a retrospective cohort study." The Lancet.

Priyanka Bushana is a Ph.D. candidate in the Neuroscience program at Washington State University. Her research is focused on the brain oscillations which support cognitive function and their relationships with oxidative stress and sleep. She is a co-founder and the president of the Health Sciences Student Advocacy Association (HSSAA), which connects science trainees and professional students to health and science policymakers.

Brandy Seignemartin is a recent Doctor of Pharmacy graduate from the Washington State University College of Pharmacy and Pharmaceutical Sciences. As a student pharmacist, she served as the VP of Legislative Affairs for the Associated Students of WSU Health Sciences (ASWSUHS). She is currently an Executive Fellow at the Washington State Pharmacy Association, practicing pharmacy at an independent community pharmacy, and working to improve our healthcare delivery system in both practice and policy.

Ravneet Waraich is a third-year medical student at the Elson S. Floyd College of Medicine at Washington State University. Previously, she obtained her Master's in Applied Bioengineering (MAB) from the University of Washington and a B.A. in Biochemistry, Biophysics, and Molecular Biology (BBMB) from Whitman College. She has a passion for social justice and health equity.

Whitney Wood is a third-year medical student at the Elson S. Floyd College of Medicine Medicine at Washington State University. Whitney is interested in practicing full scope family medicine with focuses in behavioral health and community organizing for health equity.

\section{Acknowledgements}

The authors of this memo were brought together by their work through the Civic Engagement Council (CEC), an initiative sponsored by the Associated Students of WSU Health Sciences (ASWSUHS). Their work has been supported by two CEC member organizations: the Health Sciences Student Advocacy Association (HSSAA) and the Health Equity Circle (HEC). We would also like to acknowledge the support and guidance of Jack Downs and Ilene Friedman, J.D. in completing this work. 